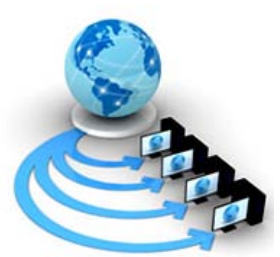

\title{
DEVELOPMENT OF A NEW SAC-OCDMA ZCC CODE SYSTEM USING DWDM FOR ENHANCING USER CAPACITY
}

\author{
Simrandeep Singh Thapar \\ Associate Professor, Deptt. of Computer Applications \\ ACET, Amritsar \\ Punjab, India
}

\author{
Himali Sarangal \\ Assistant Professor, Deptt. of ECE \\ GNDU RC Jalandhar \\ Punjab, India
}

\begin{abstract}
Zero Cross-Correlation (ZCC) code is a standout amongst the most helpful codes in Spectral Amplitude Coding- Optical Code Division Multiple Access (SAC-OCDMA) system because of its features like zero cross-correlation and another is high auto-correlation. But, as the number of users increases, the performance gets degraded for long-range communication. So in this paper, an effort has been put to enhance the degraded system using Dense Wavelength Division Multiplexing (DWDM). Method: SAC-OCDMA is an inseparable part of the global optical communication systems. It consists of various consumers' demands like capability for high speed, high bit-rate, security and high bandwidth for advanced services in local area networks and metropolitan area networks. The combination of SAC-OCDMA system with DWDM makes it conceivable to create other codes like Multi-Diagonal (MD) and Random-Diagonal (RD). The simulative analysis is performed using Optisystem11.0. Findings: Our results show that the number of users increases ten times by using a combination of 20-channel DWDM and SAC-OCDMA ZCC code system at a bit-rate of 10Gbps for $60 \mathrm{Kms}$.
\end{abstract}

Keywords: DWDM, OCDMA, SAC-OCDMA, ZCC

\section{INTRODUCTION}

The optical code-division multiple access (OCDMA) is a promising innovation which is fit for satisfying users demands, high security, high data rate and high bandwidth. The multiple-access interference (MAI) and Phase Induced Intensity Noise (PIIN) is reduced in OCDMA is accomplished through SAC-OCDMA system that uses a code with the most important minimum cross-correlation and high autocorrelation property. Hence, the ZCC code is the best code with its uniqueness of zero cross-correlation [1-4]. The ZCC code is a simple binary code designed pattern. Binary bits ' 0 ' and ' 1 ' are used for this pattern. The cross-correlation between any two codes is zero in ZCC code that is why it is called as zero cross-correlation code [5, 6]. SAC-OCDMA utilising ZCC code system receives more consideration due to its various applications.

The DWDM has an advantage of transmitting and coupling of an optical signal with specified bandwidth over a single optical fibre cable. It has a lot of applications in different optical networks because of its high speed and high performance [7-10]. Thus, DWDM can be used to increase the number of users in SAC-OCDMA system. This hybrid system (SAC-OCDMA and DWDM) accommodates more users as compared to the individual system i.e. SAC-OCDMA.

In this paper, the SAC-OCDMA system is utilising three different 1D codes (ZCC, MD and RD) that are acquired by using 20-channel DWDM system. Furthermore, to increase the users' capacity, a hybrid SAC-OCDMA ZCC code system is utilised in a combination of DWDM. This proposed system enhances the users handling capacity at a bit-rate of 10Gbps. The simulative investigation is done by using Optisystem 11.

\section{THE 20-CHANNEL DWDM AND SAC-OCDMA SYSTEM}

The block diagram of DWDM system with receiver output of DWDM, RD, MD and ZCC code is shown in Fig.1.

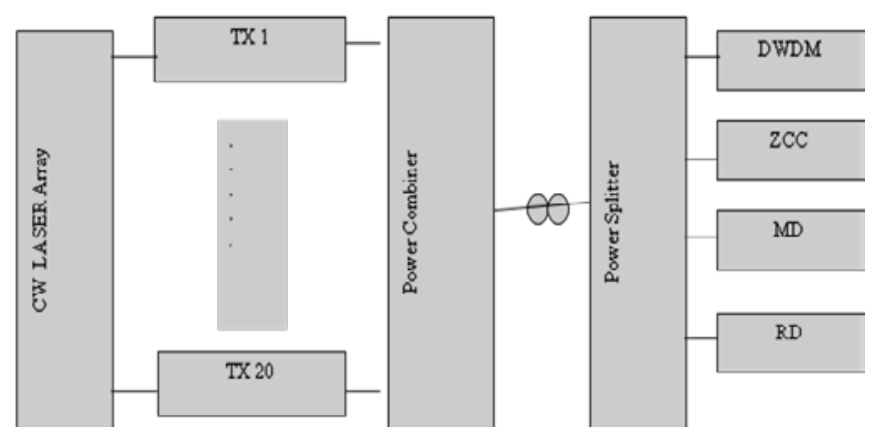

Fig. 1 Block diagram of DWDM system with receiver output of DWDM, RD, MD and ZCC code

Here, DWDM system is used to obtain the SAC-OCDMA system codes. This system includes 20-channel transmitters, receivers, and one single mode optical fibre. The transmitter section consists of CW laser array, 20 transmitters, and a power combiner. Each transmitter comprises of Pseudo Random Bit Sequence (PRBS), a signal generator (NonReturn-to-Zero (NRZ)) followed byMach-Zehnder Modulator. Then, each transmitter output is combined with power combiner and fed into the single mode optical fibre. At the receiver side, four types of outputs are obtained that is DWDM, three SAC-OCDMA systems having RD, MD, and ZCC codes. Each receiver section consists of a WDM Multiplexer with specified code pattern, a PIN photodiode is used to convert optical signal to electrical signal, a low pass filter is used to reduce the losses and a $3 \mathrm{R}$ regenerator is used 
for regeneration of electrical signal.BER analyser is used to analyse the value of $\mathrm{Q}$ factor, eye diagram and BER [11, 12]. Further, Fig. 2 shows the hybrid system of SAC-OCDMA ZCC code and DWDM.

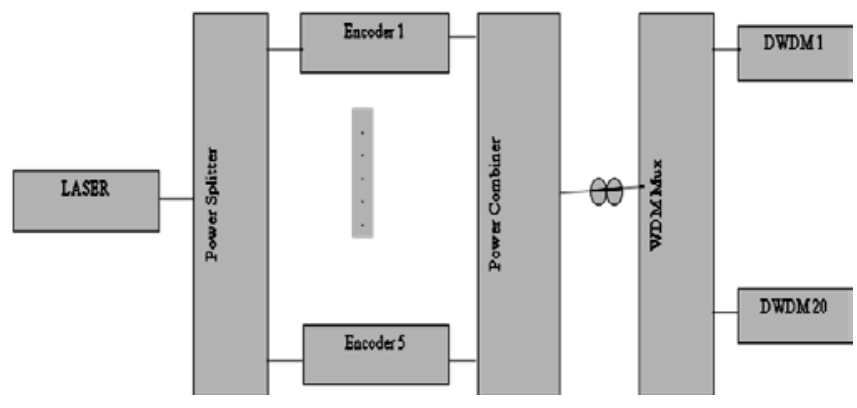

Fig. 2 Block diagram of SAC-OCDMA system using ZCC code with 20channel DWDM receiver output

The laser acts as an input coherent light source for transmitter section. The power splitter is utilised to split the input power to five parts for ZCC code encoders. Each encoder comprises of WDM multiplexer, PRBS, NRZ signal generator followed by Mach-Zehnder Modulator [13, 14]. The output of each encoder is combined in power combiner and fed into the single mode optical fibre. The receiver section consists of 20-channel DWDM.

\section{RESULTS AND DISCUSSIONS}

The simulation parameters used are given in Table 1 [13].The performance of both DWDM and SAC-OCDMA system is measured on the basis of BER, eye diagrams, Qfactors and eye height using BER analyser. Both systems are used in the wavelength range from $1500 \mathrm{~nm}$ to $1565.2 \mathrm{~nm}$ with spectral spacing $0.8 \mathrm{~nm}$ at $10 \mathrm{Gbps}$ bit rate.

Table 1. Simulation parameters

\begin{tabular}{|c|l|l|}
\hline S.No. & \multicolumn{1}{|c|}{ Parameters } & \multicolumn{1}{c|}{ Values $^{\boldsymbol{a}}$} \\
\hline 1. & Attenuation & $0.2 \mathrm{~dB} / \mathrm{km}$ \\
\hline 2. & Dark Current & $10 \mathrm{nA}$ \\
\hline 3. & Dispersion & $16.75 \mathrm{ps} /(\mathrm{nm} . \mathrm{km})$ \\
\hline 4. & Input power & $10 \mathrm{~dB}$ \\
\hline 5. & Low pass Bessel filter cut-off frequency & $0.65 * \mathrm{Bit}$ rate \\
\hline 6. & Reference wavelength & $1550 \mathrm{~nm}$ \\
\hline 7. & Responsitivity & $1 \mathrm{~A} / \mathrm{W}$ \\
\hline
\end{tabular}

${ }^{\mathrm{a}}$ Values; $\mathrm{dB}$ = decibel, $\mathrm{n}$ = nano, $\mathrm{ps}$ = picoseconds; $\mathrm{m}$ = meter, $\mathrm{A}$ = ampere, $\mathrm{kg}=$ kilogram, $\mathrm{W}=\mathrm{Watt}$

In SAC-OCDMA system utilising ZCC code is used for acquiring DWDM outputs. BER analyser demonstrates the eye diagram.

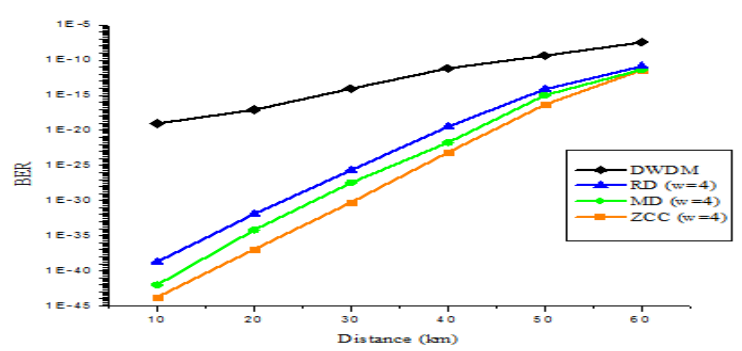

Fig. 3 Comparison of DWDM, RD, MD and ZCC code of 20-Channel DWDM system

Table 2. Codes comparison $[15,16]$

\begin{tabular}{|c|c|c|c|c|c|}
\hline $\begin{array}{c}\text { S. } \\
\text { No. }\end{array}$ & Output & $\begin{array}{c}\text { No. of } \\
\text { Users }\end{array}$ & $\begin{array}{c}\text { Code } \\
\text { weight }\end{array}$ & $\begin{array}{c}\text { Code } \\
\text { length }\end{array}$ & $\begin{array}{c}\text { Cross- } \\
\text { correlation }\end{array}$ \\
\hline 1. & DWDM & 20 & 20 & 1 & 0 \\
\hline 2. & RD & 3 & 4 & 8 & variable \\
\hline 3. & MD & 5 & 4 & 20 & 0 \\
\hline 4. & ZCC & 5 & 4 & 20 & 0 \\
\hline
\end{tabular}

As shown in Table 2, each code's weight (w) is 4 but a number of users are different. Fig. 3 shows the performance of 20-channel DWDM system in terms of BER with respect to optical fibre cable distance. Four types of outputs i.e. DWDM, RD code, MD code and ZCC code are obtained from DWDM. From Fig. 3, it is vibrant that with an increase in distance from $10 \mathrm{~km}$ to $60 \mathrm{~km}$, the BER value of DWDM increases from $9.1810^{-20}$ to $3.4410^{-8}$. The increased BER means low performance and more noise [16-18]. The generated SACOCDMA system's codes RD, MD and ZCC codes have low BER when contrasted with DWDM. In any case, the ZCC code has most reduced BER from 1.72e-45 to 3.74e-12 when compared with others (DWDM, RD, MD) from $10 \mathrm{~km}$ to 60 $\mathrm{km}$. Thus, 5 users ZCC code produced from DWDM systems gives high performance.

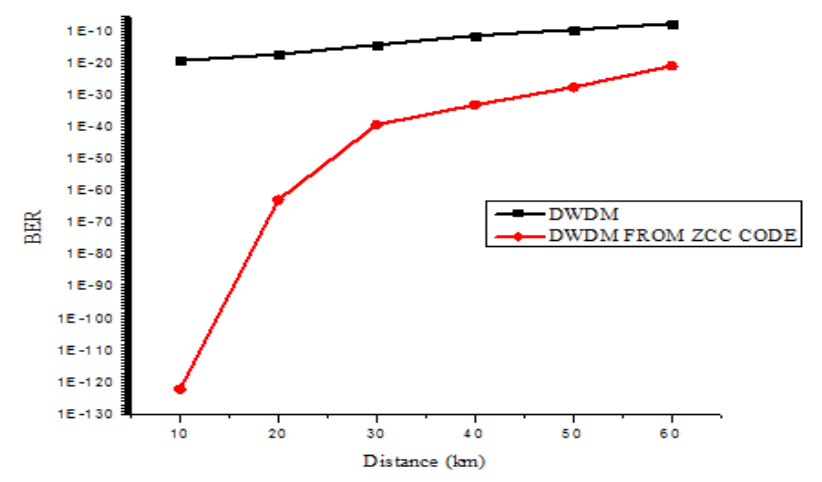

Fig.4 Comparison of DWDM output from DWDM system and DWDM output from SAC-OCDMA system utilizing ZCC code

Fig. 4 demonstrates the execution of SAC-OCDMA system regarding BER with respect to distance. DWDM output is acquired from SAC-OCDMA system utilising ZCC code. From Fig. 4, indicates that the combination of SAC-OCDMA ZCC code system with DWDM has low BER value from7.810 ${ }^{123}$ to $1.9310^{-21}$ as compared to individual DWDM system. It also indicates at a distance of $30 \mathrm{kms}$ the performance of DWDM and SAC-OCDMA becomes stable. Hence, at lower distances, the combined system performs better as compared to higher distances. The eye diagrams of 20-Channel DWDM output with and without SAC-OCDMA system are shown in Fig. 5. 


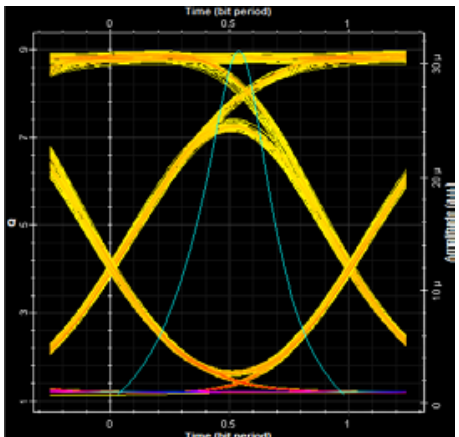

(a)

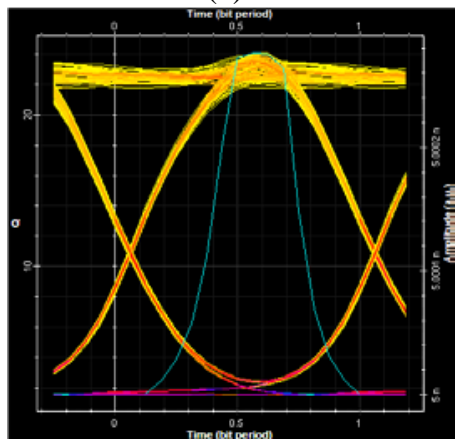

(c)

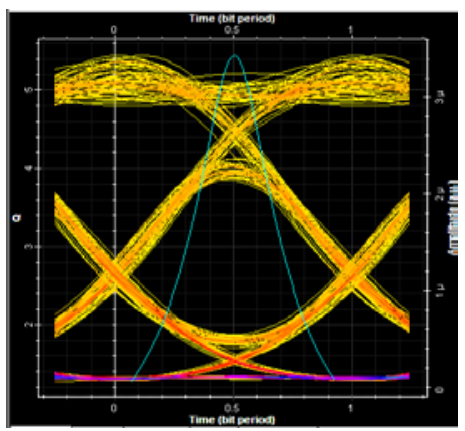

(b)

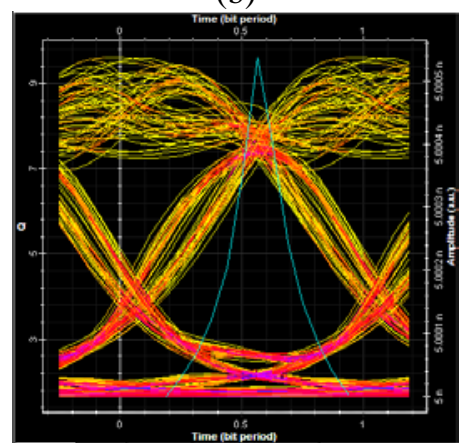

(d)
Fig. 5. Eye diagrams of DWDM output(20-Channel) (a) at 10km (without using SAC-OCDMA system), (b) at $60 \mathrm{~km}$ (without SAC-OCDMA system), (c) at $10 \mathrm{~km}$ (with SAC-OCDMA system utilizing ZCC code) and (d)at 60 km(with SAC-OCDMA system utilizing ZCC code)

From these diagrams, it is clear that at a small distance (10 $\mathrm{km}$ ) there is a better eye opening as compared to large distance (60 km). More eye opening is similar to the human eye which means fewer noises in the received information. Also, it gives the high Q-Factor at a small distance as compared to the large distance that results in less distorted communication. Now, in comparison to 20-Channel DWDM without SAC-OCDMA system, the combined system of 20-Channel DWDM and SAC-OCDMA ZCC system provides much better eye diagrams in terms of large eye opening and high Q-Factor value at different respective distances.

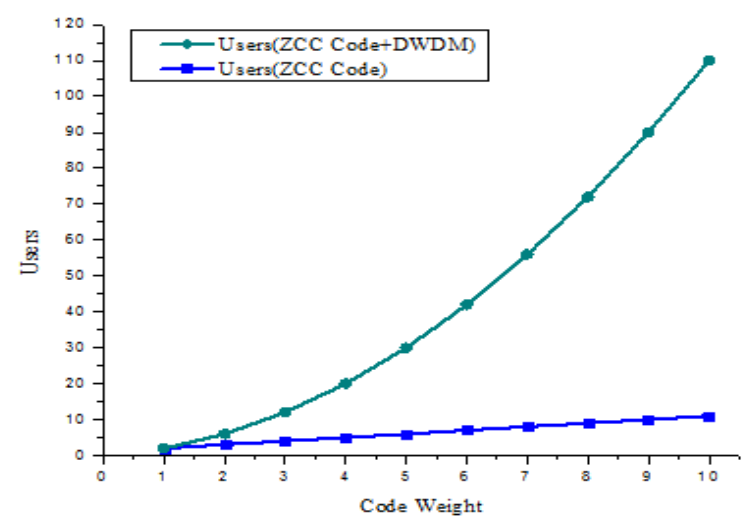

Fig. 6. Code weight Vs Users with and without using DWDM in ZCC code

Fig. 6 illustrates the relation between code weight and a number of users for the combined system (DWDM and SACOCDMA) and SAC-OCDMA system, both using ZCC code.The graph indicates that only eleven users increase in case of the individual system when code weight increases up to 10 . But, for same code weights, users increased up to 110 by using both DWDM and SAC-OCDMA ZCC code system. Consequently, users increase 10 times in hybrid system[19].
Thus, the combined DWDM and SAC-OCDMA ZCC code hybrid system provide the proficient system with more users.

\section{CONCLUSION}

In this paper, a simulative investigation has been done for enhancing the number of users' capacity a bit rate of 10Gbps with $60 \mathrm{~km}$ distance spacing by using a hybrid system of SACOCDMA ZCC code and DWDM. This SAC-OCDMA utilising ZCC code system can be used with DWDM for a large number of users even when the code weight is less. This makes a simple design, energy efficient and cost effective system. Thus, this combined system utilises advantages of SAC-OCDMA system with three codes (ZCC, MD, and RD) and DWDM system as compared to individual systems.

\section{REFERENCES}

[1] S Kumawat and M.R. Kumar, "Generalized optical code construction for enhanced and Modified DoubleWeight like codes without mapping for SAC-OCDMA systems”, Optical Fiber Technology, vol. 30, no.1pp.72-80, 2016.

[2] G. Feng, W. Cheng and F. Chen, "Performance analysis for the bit- error rate of SAC-OCDMA systems”, Infrared Physics \& Technology, vol. 72, no.1, pp.160-162, 2015.

[3] H.M. Al-Khafaj, R. Ngah, S.A. Aljunid and T.A. Rahman, “An Innovative Encoding/Decoding Architecture Based on TwoCode Keying for SAC-OCDMA Systems”, Proceedings of 2014 IEEE 5th International Conference on Photonics (ICP), pp.250-252, September 2014.

[4] A.M. Alhassan, N. Badruddin, N.M. Saad and S.A. Aljunid, "Beat Noise Mitigation through Spatial Multiplexing in Spectral Amplitude Coding OCDMA Networks. Proceedings of IEEE 4th International Conference on Photonics (ICP), pp.169171, 2013.

[5] H.Y. Ahmed, H.M.R. Al-Khafaji, H.A. Fadhil and S.A. Aljunid, "Variable cross-correlation code construction for spectral amplitude coding optical CDMA networks”, Optik, vol. 123, no.1, pp. 956-963, 2012.

[6] R.S. Kaler and V. Jyoti, "Design and performance analysis of various one-dimensional codes using different data formats for OCDMA system”, Optik, vol.122, no.1, pp.843-850, 2011.

[7] A.R.A.J. Abdullah, A.M. Safar, J.M. Nordin, M.N.M. Saad and S.A. Aljunid, "Enhancement of Zero Cross Correlation Code for Optical CDMA Network System”, Proceedings of International Conference on Communications and Information Technology(ICCIT), 2012.

[8] G. Yan, Z. Ruixia, D. Weifeng and C. Xiaorong, "Point-toPoint DWDM System Design and Simulation”. Proceeding of International Symposium on Information Processing, pp. 90-92, 2009.

[9] S. Song, “An Overview of DWDM Networks”, IEEE Canadian Review-Spring Printemps, pp. 15-18, 2001.

[10] G. Deshmukh and S. Jagtap, "Four Wave Mixing In DWDM Optical System”, International Journal of Computational Engineering Research, vol.3, no.6, pp.7-11, 2013.

[11] M.N. Junita, N.M. Saad, H.A. Fadhil, S.A. Aljunid and T.H Abd, "Modelling and simulation of a $1.6 \mathrm{~Tb} / \mathrm{s}$ optical system based on multi-diagonal code and optical code-division multiple-access”, Ukr, J,Physvol.13, no.2, pp.54-66, 2012.

[12] B. Dai, N. Wada, N. Kataoka, Z. Gao and X. Wang, “Transparent Transmission of a Secure Time Domain Spectral Phase Encoding/Decoding DPSK-OCDM Signal Over a DWDM Network", J. Opt. Commun. Netw., vol.3, no.5, pp.404-410, 2011 . 
[13] M.S. Bhamrah and K. Singh, "Investigation of Transmitted Power in Intersatellite Optical Wireless Communication", International Journal of Computer Science and Information Technology \& Security (IJCSITS), vol. 2, no.3, pp. 1666-1670, 2012.

[14] A.R. Arief, M.S. Anuara, M.N. Junitaa, N.M. Saad and S.A. AlJunid, "PIN versus Avalanche photodiode gain optimization in zero cross-correlation optical code division multiple access system”, Optik, vol. 124, no.1, pp. 371- 375, 2013.

[15] M.S. Anuar, N.M. Saad, S.A. Aljunid and S.M. Hamzah, "New design of spectral amplitude coding in OCDMA with zero cross-correlation”, Optics Communication, vol. 282, no.1, pp. 2659-2664, 2009.
[16] I. Ali, "Bit-Error-Rate (BER) Simulation Using MATLAB", International Journal of Engineering Research and Applications, vol.3, no.1, pp. 706-711, 2013.

[17] M. Kumari and H. Sarangal, "Inter-satellite Optical Links in ZCC SAC-OCDMA system”, International Journal of Research in Electronics and Computer Engineering (IJRECE), vol. 3, no.1, pp.83 - 86, 2015.

[18] T.H. Abd, S.A. Aljunid, H.A. Fadhil, R.A. Ahmad and N.M. Saad, "Design And Simulation A New Code With Zero CrossCorrelation For SAC-OCDMA Networks", Australian Journal of Basic and Applied Sciences, vol.6, no.3, pp.112-119, 2012.

[19] M. Kumari and H. Sarangal, "Performance Analysis of Zero Cross- Correlation Code in SAC-OCDMA with DCF and EDFA”, International Journal of Science, Technology \& Management, vol.4, no.1, pp.1186-1191, 2015. 